\title{
OS DIREITOS REAIS E A LEI N. 11.481/07: REFLEXÕES SOBRE A FUNCIONALIZAÇÃO DO REGIME DA PROPRIEDADE PÚBLICA
}

\section{THE RIGHTS IN REM AND LAW NO. 11,481 / 07: REFLECTIONS ON THE FUNCTIONALIZATION OF THE PUBLIC OWNERSHIP}

\section{Patricia Silva Cardoso ${ }^{1}$}

\section{Resumo}

O texto tem como objetivo a análise crítica da Lei $n$. 11.481, de 2007, que, ao tratar da regularização fundiária de interesse social em imóveis da União, promoveu a alteração do rol taxativo dos direitos reais previstos no artigo 1.225 do Código Civil e nele inseriu os incisos XI e XII, que tratam, respectivamente, do direito real de uso especial para fins de moradia e do direito real de uso de bem público. A mudança traz reflexos não só para o direito civil, mas representa alteração de significativa monta da propriedade pública, ao atribuir caráter de direito real a situações jurídicas que antes gozavam apenas de tutela contratual. Promovendo a dinamização do domínio dos bens públicos e enfatizando a função social do uso e sua potencialização - pelo fracionamento das faculdades proprietárias e a atribuição do uso a um particular -, essa alteração privilegia os valores econômicos e sociais da posse, alberga o direito à moradia e faz efetiva a Carta Constitucional. Nossa proposta é traçar um panorama geral sobre as transformações doutrinárias ocorridas, com o intuito de precisar os limites atuais dos direitos reais. A enumeração de algumas tendências doutrinárias não tem pretensão exaustiva, servindo apenas de base para a reflexão sobre a atualidade da classificação dos direitos patrimoniais. O cotejo com a teoria do direito civil requer atenção e um exame sistemático, para que esse regime público-privado seja compreendido na sua inteireza e traga soluções satisfatórias para o cumprimento da função social da propriedade e o reconhecimento de novas titularidades sobre os bens públicos.

Palavras-chave: direitos reais; propriedade pública; direito real de uso para fins de moradia; Lei n. 11.481/07.

\begin{abstract}
The purpose of the following text is the critical analysis of the Law 11.481, from 2007. While covering land ownership regularization of social interest in the Union's properties, it promoted the alteration in the right in rem's numerous clausus foreseen in the article 1.225 from the Civil Code and inserted the clauses XI and XII, that deal with the real right of use for housing purposes and the real right of use of public property. Such change brings consequences not only to civil rights, but it represents alteration in significant amount of public property when it attributes characteristics of right in rem to juristic situations that used to have contractual protection. Promoting the development of public goods and emphasizing the social role of use and its strengthening through the sharing of ownership abilities and assigning the use to a particular one -, this alteration privileges the economical and social values of timeshare, embraces the right to household and turns the Constitutional Charter effective. The comparison to the civil rights regime requires attention and a systematic examination, so that such public-private regime is understood in its wholeness and brings satisfactory solutions to the fulfillment of property's social role and the acknowledgment of new ownership over public goods.

Keywords: right in rem; public property; real right of use for housing purposes; law 11.481/07

\footnotetext{
${ }^{1}$ Professora de Direito Civil da Universidade Federal Fluminense (UFF- ESCHSVR), doutoranda em Direito da Cidade pela Universidade do Estado do Rio de Janeiro (UERJ) e pela Università degli Studi di Roma - La Sapienza. E-mail: psilvacardoso@yahoo.com.br
} 


\section{INTRODUÇÃO}

A divisão clássica entre os bens públicos e os bens privados, dicotomia inspirada pela summa divisio do direito, expressa a rígida bipartição entre direito público e direito privado, caracterizados como ramos estanques e incomunicáveis. Ao direito público, se reserva a possibilidade de ação determinada pela lei; ao direito privado, a ampla e irrestrita possibilidade de agir, uma vez que é possível fazer tudo o que não é expressamente proibido por lei.

Contemporaneamente, avolumam-se as dificuldades para precisar os exatos limites da divisão do universo jurídico em categorias fechadas e necessariamente opostas. É comum a menção à publicização do direito privado (RAMOS, 1998, pp. 3-29), e também à privatização do direito público. Compreende-se que o interesse particular é um dos vetores que devem ser levados em consideração para a exata compreensão do interesse público e o atendimento do bem comum. Por outro lado, reconhece-se também uma dimensão social em interesses eminentemente privados.

Reflexo dessas mudanças, a Lei n. 11.481, de 2007, tem por objetivo promover a regularização fundiária de interesse social em imóveis da União. À primeira vista, ela parece trazer poucas alterações ao regime jurídico da propriedade pública, tradicionalmente pautado pelo princípio da supremacia do interesse público e apartado da propriedade clássica do direito privado. Entretanto, a referida lei dá um importante passo rumo à concretização da função social da propriedade e eleva à condição de direitos reais a concessão de uso e a concessão de uso para fins de moradia.

O legislador teve como objetivo a outorga de uma tutela jurídica mais efetiva a determinadas situações que emergiam do contexto social, e por isso atribuiu-Ihes um caráter real. Para tanto, ele ampliou o rol taxativo do artigo 1.225 do Código Civil - marcado pelo princípio da tipicidade dos direitos reais - e nisso andou bem. Entretanto, diversamente dos demais direitos reais tipificados no Codex, aos novos direitos não foi atribuído um título específico, o que gera algumas incompletudes e desloca a regulamentação da matéria para a esfera da legislação administrativista.

A referida lei disciplina a alteração relativamente aos bens da União para fins urbanos e rurais e, ao mesmo tempo em que modifica o Código Civil, provoca consequências importantes no regime de propriedade pública, incidindo primordialmente sobre os bens dominicais, sendo também possível a desafetação de um bem de uso especial para fins de concessão de uso. Todavia, 
a análise das normas de direito público não pode prescindir do estudo sistemático da teoria geral dos direitos reais, cabendo ao Direito Civil conceituá-los e estabelecer os seus limites.

A ratio teórica dos direitos reais repousa nas estruturas do direito privado. Por sua vez, as soluções apontadas sofrerão um cotejo com o direito público, com vistas a conciliar e estabelecer um regime híbrido, decorrente da descentralização legislativa. Neste ponto, principiar-se-á por uma análise de direito privado estabelecer os fundamentos teóricos dos direitos reais tipificados, enquanto a legislação de direito público será examinada no sentido de adequação e exequibilidade do modelo concretamente apresentado.

A atribuição de caráter real ao uso de bens públicos, com fins ou não de moradia, decorre de uma legislação de direito público e, apesar de sua inserção no Código Civil, tais situações são também regulamentadas por diplomas publicistas. Inaugura-se um regime jurídico híbrido, numa confluência de regras públicas e privadas, o que demanda do operador um olhar percuciente, a fim de que sua extensão e aplicação sejam claramente definidas.

No presente trabalho, ter-se-á por ponto de partida a teoria do direito civil e as críticas apontadas à teoria dos direitos reais para, em momento posterior, analisar as mudanças promovidas pela legislação publicista, com o intuito de verificar quais instrumentos de direito privado foram trazidos pelo legislador e como estes podem contribuir para a realização das finalidades previstas pela lei, quais sejam, levar a cabo o processo de regularização fundiária no país, garantindo não apenas o acesso à moradia, mas também o desenvolvimento econômico através de institutos jurídicos e instrumentos patrimoniais que primam pela compreensão da função social da propriedade.

Outrossim, este artigo tem como objetivo definir os aspectos dogmáticos e as repercussões práticas dos novos direitos reais inseridos no Código Civil pela Lei n. 11.481/07, sem descurar das consequências práticas acarretadas pela sua integração aos conteúdos do direito público, admitindo-se que "as soluções concretas proporcionadas por direitos reais evoluem, por fim, em obediência a uma integração sistemática que transcende o direito civil" (MENEZES CORDEIRO, 1994, p. 229). As relações jurídicas reais são dotadas de conteúdo eminentemente patrimonial e têm forte repercussão na ordem econômica. Tal assertiva pode ser demonstrada pelo fato de a Lei Maior prever expressamente a função social da propriedade como um dos vetores da ordem 
econômica: ${ }^{2}$ ao fazê-lo, proporciona novos contornos à propriedade, seja ela pública ou privada, e impõe uma releitura dos vínculos reais e das titularidades. É o que examinaremos a seguir.

\section{O PONTO DE PARTIDA: A CLASSIFICAÇÃO DOS DIREITOS SUBJETIVOS}

As relações de apropriação e de senhorio do homem sobre uma coisa, as relações de pertinência e exclusão que se colocam entre o que pertence ou não ao sujeito, isto é, entre o "meu" e o do "outro", são fundamentais para a atribuição e a distribuição de riquezas e bens dentro da sociedade ocidental moderna. Tais relações baseiam-se na atribuição dessas coisas aos homens, o que é feito tecnicamente por meio da categoria "direitos reais", roupagem jurídica da apropriação individual.

Em outras palavras, o estudo da matéria remonta à "questão central sobre a consistência mínima do 'meu' jurídico" (GROSSI, 2006, p. 5) e, no bojo dessa noção de pertencimento individual, é erigida a noção de propriedade moderna ${ }^{3}$ e a teoria geral dos direitos reais. Tal afirmação nos leva à análise dos direitos subjetivos e a suas classificações, dimensão teórica que deve ser explorada com pretensão expositiva, com o intuito de precisar alguns limites dogmáticos entre as diversas categorias de direitos subjetivos tradicionalmente apontadas.

De especial relevância é a análise da dicotomia direitos reais versus direitos de crédito, classificação não só distintiva dos direitos subjetivos, mas também estruturante do próprio direito civil. A contraposição entre essas categorias é recurso frequentemente utilizado para defini-las, de modo que o estudo dos direitos reais demanda uma análise, ainda que panorâmica, dos direitos de crédito. As origens mais remotas dessa classificação estão no direito romano (ASCENSÃO, 2012, p. 15), numa distinção apresentada no plano processual e pautada na classificação das ações. Em Roma, vigorava o princípio da tipicidade da tutela judicial e as situações de direito material eram tuteláveis apenas caso se enquadrassem em uma das actiones expressamente previstas em lei. Distinguiam-se a actio in rem (ação real), na qual o autor afirmava o seu direito sobre uma coisa

\footnotetext{
2 "A ordem econômica, fundada na valorização do trabalho humano e na livre iniciativa, tem por fim assegurar a todos existência digna, conforme os ditames da justiça social, observados os seguintes princípios: [...] III - função social da propriedade" (BRASIL, Art. 170).

3 "Em que pese a constante preocupação dos autores norte-americanos em visualizar o direito como um sistema baseado na eficiência e indissoluvelmente ligado à economia, não seria exagero afirmar que o direito de propriedade existe para que se possa instituir o controle adequado de bens reputados pelo legislador como valiosos e escassos (MAURO, 2008, p. 35).
} 
contra todas as demais pessoas, e a actio in personam (ação pessoal), em que o direito sobre a coisa era afirmado apenas em relação a uma determinada pessoa.

Por se tratar de um sistema jurídico casuístico, todas as situações jurídicas eram examinadas sob o prisma da ação. A tipicidade dos modelos previstos garantia a segurança jurídica: a actio in personam dirigia-se contra uma pessoa, que deveria ser determinada; a actio in rem dirigia-se contra uma coisa, dispensando-se a especificação de uma pessoa. Posteriormente, os glosadores medievais retomaram a classificação sob uma nova perspectiva, deslocando-a do plano processual para o plano do direito substantivo: surge assim a oposição entre o ius in personam (direitos referentes a pessoas) e ius in rem (direitos sobre as coisas). A distinção inspira a classificação dos direitos em absolutos ou relativos, classificação que repousa no dever a eles inerente (DANTAS, 1984, p. 11). Os direitos sobre as coisas são absolutos porque são exercidos diretamente sobre uma coisa e dispensam um sujeito passivo específico; os direitos referentes às pessoas são relativos porque podem ser exercidos apenas diante de um sujeito passivo determinado.

Observe-se que a expressão "direitos reais" (ius in rem) surge inicialmente como uma categoria de direitos, porém, alguns séculos depois, por influência da Pandectística, a classificação dos direitos subjetivos patrimoniais passa a designar também a sistematização dos grandes ramos do direito privado. Os juristas pandectistas, inspirados pelo liberalismo abstracionista, procuravam definir e resumir a realidade social em categorias jurídicas. Tal abstração tinha por escopo a construção de estruturas conceituais que atribuíssem um caráter sistemático ao direito, que seria alcançado por meio de definições conceituais claras e precisas, nos moldes das ciências da natureza.

Uma das grandes conquistas desse período é o conceito de relação jurídica, noção que instrumentaliza e torna possível o exercício dos direitos subjetivos em termos de uma teoria geral. Outrossim, é a partir da sistematização germânica das relações jurídicas que são assentadas as bases teóricas para que o direito das obrigações e os direitos reais se apresentem e se consolidem como dois ramos distintos e precisamente definidos do direito privado. Desse modo, por um longo caminho doutrinário, a classificação romana das ações deu origem à classificação dos direitos subjetivos e evoluiu para também designar a própria estruturação do direito privado.

A dicotomia direitos pessoais versus direitos reais está na gênese da distinção entre dois grandes sub-ramos do direito civil: o direito das obrigações e o direito das coisas. Tal dualidade acaba por se refletir no tratamento legislativo da matéria nos códigos. Alguns códigos civis, 
espelhando a referida dicotomia, dedicam livros diferenciados a cada um desses ramos. É o caso do Código Civil brasileiro, que segue o sistema alemão e admite uma parte geral, dedicando um livro ao direito das coisas (BEVILÁQUA, 1956, p. 12). Por sua vez, os países que se inspiraram no Código Napoleônico, que não admite uma parte geral, não têm um livro especialmente destinado ao direito das coisas e disciplinam as relações jurídicas reais num livro ou título especial, dedicado ao "direito dos bens", expressão mais ampla do que a locução "direito das coisas". A matéria pode ainda ser disciplinada por um livro destinado aos direitos reais ou ao direito de propriedade. ${ }^{4}$

A opção pela não inclusão de um livro específico sobre o direito das coisas não significa uma rejeição à classificação, apenas indica uma orientação metodológica ${ }^{5}$ do legislador, ao optar pelo uso de uma nomenclatura que pode ser mais ou menos ampla. ${ }^{6} \mathrm{~A}$ não existência de um livro específico sobre o direito das coisas não invalida a classificação; a distinção entre os dois ramos permeia os grandes códigos civis, ainda que a caracterização precisa das categorias seja deixada a cargo da doutrina.

O legislador, inspirado pela antiga máxima do Digesto de Justiniano (D.50,17,202) - "toda definição em direito civil é perigosa: rara é, na verdade, aquela que não possa ser subvertida" -, deve regulamentar situações jurídicas especialmente relevantes e abster-se de definições conceituais, tarefa deixada sob a responsabilidade do jurista. Todavia, tais atribuições - definição e regramento -, apesar de distintas, são complementares e interdependentes, pois os princípios e regras de cada ramo podem ser aplicados apenas à medida em que se conhece e delimita seu objeto de aplicação. Igualmente, é a partir da precisa definição das categorias jurídicas que surgem princípios e regras específicos para cada um dos ramos do direito privado.

\footnotetext{
${ }^{4}$ Eduardo Espínola assim discorre sobre a questão: "Os códigos que não admitiram uma parte geral, como o brasileiro, o alemão, o chinês, consideram os bens e a propriedade num livro ou num título especial sob a rubrica Dos bens; e assim o francês, o chileno, o mexicano, o venezuelano, o boliviano; ou com a epígrafe Dos direitos reais, como o Código suíço, o peruano; ou, ainda, Da propriedade, designação adotada pelo novo Código italiano (ESPÍNOLA, 2002, p. 11).

5 "É certo que os direitos com que deparamos neste curso se referem necessariamente a coisas. Mas a expressão "direito das coisas" parece mais adequada para designar aquele conjunto de regras que traçam o estatuto jurídico das coisas, digamos assim, e que tem o seu assento principal nos arts. 202 e seguintes. Nesses preceitos, e de acordo com orientação metodológica inteiramente justificada, o legislador está ainda a fixar qual o objeto sobre o que hão de recair os direitos subjetivos, não a regular diretamente esses mesmos direitos. O direito das coisas, entendido nesse sentido imediato e restrito, integra-se naturalmente na Teoria Geral do Direito. Só se poderá por isso falar-se em direito das coisas para designar um dos ramos do direito civil, que engloba uma dada categoria de direits subjetivos, se se atribuir a essa expressão um caráter real" (ASCENSÃO, 2012, p. 17).

6 "A palavra "reais" deriva de res, rei, que significa coisa. Há, assim, entre as expressões 'direito das coisas' e 'direitos reais' manifestas afinidades" (ASCENSÃO, 2012, p. 17).

${ }^{7}$ No original: "Omnis definitio in iure civili periculosa est: parum est enim, ut non subverti possit".
} 
A necessidade desse diálogo entre o jurista e o legislador é apontada com clareza por José de Oliveira Ascensão, em excelente estudo sobre os direitos reais, no qual ele sinaliza a importância da delimitação das categorias de direitos subjetivos:

Essa antítese torna-se crucial, uma vez que dela passa a depender a distribuição das matérias e a consequente aplicação a cada figura dos princípios que se consideram característicos da categoria que foi integrada. Não admira por isso que os autores tão aturadamente tenham trabalhado os conceitos de obrigação e de direito real (2012, p. 17).

Como bem salienta o autor supracitado, na tentativa de melhor caracterizar essa distinção, surgem variadas concepções teóricas, tão numerosas quanto os estudiosos da matéria. Contudo, antes de prosseguir na análise das diferentes teorias, é importante frisar que, no bojo deste trabalho, seria impossível esgotar as inúmeras teses que versam sobre o tema e suas vicissitudes. A enumeração de algumas tendências doutrinárias não tem pretensão exaustiva, servindo apenas de base para a reflexão sobre a atualidade da classificação dos direitos patrimoniais.

Feitos os devidos esclarecimentos, passemos à análise de algumas manifestações teóricas, que serão agrupadas em três grandes concepções: a monista (ou unitarista), a dualista e a eclética (NADER, 2006, pp. 14-16). As concepções unitaristas pretendem unificar as categorias de direitos patrimoniais, seja sob o pálio dos direitos reais (correntes personalistas), seja sob o pálio das obrigações (correntes impersonalistas, ou objetivistas). A concepção dualista sustenta a manutenção da distinção entre as duas espécies de direitos patrimoniais, bem como sua caracterização precisa (teoria clássica, ou realista).

A teoria clássica, ou realista, determina que o direito real é uma relação jurídica entre o sujeito e a coisa que se estabelece diretamente, sem intermediários, inexistindo um vínculo entre o titular do direito e outro sujeito. A teoria personalista, em contraposição à corrente tradicional, propõe que o direito real é uma relação jurídica entre o seu titular e a coletividade, que é o sujeito passivo universal. ${ }^{8}$ Sua configuração está assentada na premissa de que toda relação jurídica se estabelece entre sujeitos, pois a todo direito corresponde necessariamente um dever jurídico. Nessa ordem de ideias, os direitos reais são considerados como relações jurídicas entre as pessoas e têm, tal como os direitos de crédito, três elementos: sujeito ativo, sujeito passivo e objeto; com esta ressalva quanto ao sujeito passivo: enquanto nos direitos pessoais o sujeito passivo é pessoa certa e determinada, nos direitos reais existe um sujeito passivo universal.

\footnotetext{
8 "Nesse campo, a insegurança das noções não impede que se tenha formada opinião dominante. A relação jurídica será intersubjetiva: estabelecer-se-á necessariamente entre pessoas" (ASCENSÃO, 1962, p. 42).
} 
A perspectiva personalista coloca o direito das obrigações no centro do direito civil e sofre críticas no que diz respeito à figura do sujeito passivo universal e à consequente abstenção da coletividade (SÁ, 2002, p. 88). Por sua vez, a perspectiva realista não leva em consideração a impossibilidade teórica de se estabelecer uma relação jurídica entre um sujeito e uma coisa. $\mathrm{Na}$ tentativa de harmonização dessas características, surgem as teorias ecléticas, que propõem duas dimensões na delimitação dos direitos reais: a dimensão interna, caracterizada pelo poder direto e imediato do sujeito sobre a coisa, e uma dimensão externa, que seria a relação jurídica entre o titular do direito real e a coletividade, qual seja, o sujeito passivo universal.

É importante ressaltar que as teses anteriores restringem a problemática aos direitos subjetivos, e suas categorias, e ao conceito de relação jurídica. Todavia, abalizada corrente doutrinária, capitaneada por Pietro Perlingieri, utiliza a expressão situação jurídica ${ }^{9}$ para definir as situações nas quais o sujeito de direito pode estar envolvido - categoria mais ampla da qual o direito subjetivo é apenas uma espécie. Ensina Gustavo Tepedino que a noção de situação jurídica deve ser preferida para que se evite o equívoco "de se reduzir o tema à problemática dos direitos subjetivos, sublinhando-se, de outra parte, a inserção das situações subjetivas reais em relações entre sujeitos, ou intersubjetivas" (PERLINGIERI,1999, p. 137).

Se todas as relações jurídicas são formadas por situações jurídicas subjetivas, a classificação central a ser estabelecida não é a que divide os direitos subjetivos em direitos pessoais e direitos reais, mas aquela que classifica as relações jurídicas e, por conseguinte, as situações jurídicas em patrimoniais e não patrimoniais, partindo-se da premissa de que estas últimas podem abranger uma ampla gama de manifestações subjetivas. Isso significa que a distinção deve ser compreendida no âmbito das situações jurídicas patrimoniais, que podem ser pessoais ou reais, conforme os poderes conferidos aos seus titulares (PERLINGIERI, 2002, p. 139).

Com efeito, vários critérios procuram explicar a distinção. Destacam-se, contudo, três grandes recortes:

1. O objeto;

2. A eficácia da relação jurídica ou dever jurídico; e

3. A tipicidade.

\footnotetext{
9 "O conceito geral de tais categorias é a situação jurídica. O efeito é, portanto, um conjunto simples ou complexo de constituição, modificação ou extinção de situações jurídicas. [...]. Fazem parte do conceito geral de situação jurídica, por exemplo, o direito subjetivo, o poder jurídico (potestà), o interesse legítimo, a obrigação, o ônus etc.: trata-se sempre de situações jurídicas" (PERLINGIERI, 1999, p. 105).
} 
É importante frisar que os direitos reais têm por objeto imediato as coisas corpóreas e os direitos de crédito têm por objeto imediato a prestação a ser realizada pelo devedor. Daí decorre que nos direitos reais o titular exerce diretamente os seus poderes sobre a coisa, sem intermediação de nenhuma outra pessoa, o que caracteriza a aderência à coisa; já nos direitos de crédito a prestação se realiza apenas com a cooperação do devedor. É comum a afirmativa de que nos direitos reais há um direito sobre a coisa e nos direitos de crédito, um direito à coisa.

Quanto à eficácia, os direitos reais seriam absolutos e os direitos de crédito, relativos. Nas relações reais há um sujeito passivo universal, impondo-se à coletividade o dever geral de não prejudicar o âmbito de incidência desses direitos, que seriam oponíveis erga omnes. Nas relações pessoais, o sujeito passivo é previamente conhecido e apenas ele se vincula ao dever de realizar a prestação, restando caracterizada uma oponibilidade inter partes. Na relação real há um sujeito ativo determinado que está ligado à totalidade dos restantes sujeitos, o que é traduzido nas duas fórmulas paralelas do "dever universal de respeito", da "obrigação passiva universal" e do "sujeito passivo universal", perfazendo uma relação absoluta. ${ }^{10}$

As manifestações típicas da oponibilidade absoluta do direito real são o direito de sequela e a preferência. O primeiro permite ao titular do direito perseguir a coisa onde quer que ela esteja e reivindicá-la de quem injustamente a possua (ubicunque sit res, domino suo clamat, ou seja, a coisa clama por seu dono). Por exemplo, o dono da coisa pode reivindicá-la não só de quem dela se apropriou indevidamente, mas também do terceiro a quem o detentor, abusivamente, a tenha vendido, emprestado ou alugado. O direito de preferência significa que os créditos garantidos por um direito real têm prioridade sobre todos os outros, sendo os primeiros a serem satisfeitos em caso de concurso de credores, de forma que o produto de eventual venda em hasta pública destina-se inicialmente à satisfação desses créditos, sendo revertido aos outros credores apenas se houver algum excedente após a extinção do débito.

Por fim, quanto à tipicidade, os direitos reais são considerados numerus clausus, apenas existindo as modalidades expressamente previstas em lei, que não podem ser modificadas; por sua vez, os direitos de créditos são numerus apertus e, em virtude da autonomia negocial, podem ser livremente criados e modificados pelas partes interessadas.

10 Tal estrutura comporta um alto grau de abstração, pois a massa dos sujeitos apenas é tomada em consideração para ser posteriormente repelida de determinada situação. Nesse sentido, José de Oliveira Ascensão traz severas críticas à terminologia empregada para classificar as relações jurídicas, ressaltando o caráter disforme da construção e propondo seu repúdio (2012, p. 27). 
Cabe ressaltar que as características supramencionadas têm sofrido críticas de abalizada doutrina, ${ }^{11}$ que, partindo de uma reflexão sobre a função dos direitos reais dentro da estrutura do ordenamento jurídico, sustenta a tese de que os traços classicamente apontados para a delimitação do conceito de direito real vêm gradativamente perdendo relevância, questionando ainda a imobilidade e o isolamento desse importante ramo do direito civil. ${ }^{12}$

\section{O “SUPOSTO” IMOBILISMO LEGISLATIVO DOS DIREITOS REAIS}

O sistema de normas relativas aos direitos reais está assentado na prevalência da propriedade imobiliária sobre a mobiliária. Por conta do caráter e das características da propriedade imobiliária, que se destina a regular a permanência do homem na terra, aponta-se que os direitos reais seriam direitos de manutenção do status quo e disciplinariam a parte estática do patrimônio.

Face às mudanças ocorridas no modo de produção e no estilo de vida da sociedade contemporânea, na qual avulta em importância o valor mobiliário e a tutela de utilidades imateriais, que, a princípio, não poderiam ser classificadas como bens jurídicos, observou-se um certo desinteresse por esse ramo do direito civil, frequentemente apontado como refratário à inovação. E, assim, as investigações dos estudiosos passaram a se concentrar nas áreas mais dinâmicas do direito privado, entre elas, o direito das obrigações e dos contratos.

Gustav Radbruch acentua que o direito das coisas é o elemento estático e o direito das obrigações é o elemento dinâmico do mundo jurídico (1997, p. 52). Os direitos reais são apontados como permanentes e os direitos de crédito, como transitórios. Os primeiros são constituídos para durar, uma vez que se referem à propriedade, tendo por finalidade assegurar ao titular o uso ou a fruição da coisa, não se exaurindo com o cumprimento do dever pelo sujeito passivo. Já os direitos de crédito têm existência precária, pois nascem para serem cumpridos, ou seja, o fim normal da obrigação é sua extinção, o adimplemento. Cumprido o dever adstrito ao sujeito passivo - que é,

\footnotetext{
${ }^{11}$ Segundo Pietro Perlingieri (1999), sob o manto das relações jurídicas patrimoniais há uma aproximação das categorias, que passam a interagir de modo dialético, influenciando-se mutuamente. Afastada a distinção em termos de contraposição excludente, as relações jurídicas patrimoniais podem ser repensadas e formatadas em conformidade com os interesses concretamente dignos de tutela. Ele sustenta que os direitos reais teriam sido relativizados face aos novos contornos da autonomia privada e da propriedade, que, de noção abstrata, passa a ser abordada como uma situação jurídica complexa, o que importa necessariamente uma interação com outras situações, em coligação ou em conflito.

${ }^{12}$ Cf. Menezes Cordeiro (1994, p. 229) e Ascensão (1968).
} 
em si, a própria razão pela qual a obrigação é contraída -, ele tende a desaparecer, uma vez desprovido de qualquer utilidade jurídica. Tal é o magistério de Antunes Varela:

Enquanto os direitos reais, especialmente os direitos reais de gozo, se constituem para durar, a fim de proporcionarem ao titular o uso ou fruição da coisa própria ou de certas utilidades das coisas alheias, os direitos de crédito nascem para ser cumpridos, ou seja, para se extinguirem (2005, p. 16).

Daí a afirmação de que o direito das obrigações teria um caráter essencialmente dinâmico, com vistas a regular a produção e circulação de riquezas no âmbito dos interesses individuais; já o direito das coisas seria marcado pela perpetuidade inerente ao direito de propriedade, por garantir situações permanentes que implicam uso, fruição e disposição da coisa. Dentro dessa lógica, as funções que esses institutos desempenham na vida jurídica são essencialmente distintas: os direitos reais asseguram aos indivíduos poderes sobre objetos do mundo exterior; os direitos de crédito disciplinam relações entre pessoas determinadas, englobando restrições à liberdade do devedor.

Tendo em vista as diferenças funcionais apontadas, a lei não permite que os direitos de crédito se protraiam no tempo com a mesma facilidade que admite a ilimitação temporal dos direitos reais - pois a propriedade é feita para durar, prolongando-se no tempo -, o que contribui para o dinamismo das obrigações e também para o imobilismo dos direitos reais, que pouco evoluíram desde a consolidação da propriedade jusracionalista no Código Napoleônico de 1804 (COSTA, 1968, p. 48). ${ }^{13}$ Segunda tal concepção, o direito das coisas é um ramo que está em crise.

Todavia, essa crise diz respeito propriamente a uma forma específica de pensar e concretizar o direito e surge em decorrência de um complexo processo de mudanças ocorridas a partir do século XIX, que culmina com o surgimento da sociedade tecnológica, ou de massas. As mudanças impõem crescentes desafios a uma teoria jurídica construída num momento histórico completamente distinto, com necessidades radicalmente divergentes das contemporâneas. De fato, trata-se de uma crise dos conceitos, fruto de uma metodologia que parte de esquemas conceituais com pretensão de validade absoluta e expressa o fenômeno jurídico de forma descritiva e mecânica, desconsiderando sua historicidade.

O pensamento jurídico europeu dos séculos XVIII e XIX foi marcado pelo racionalismo, movimento que atribuiu à razão a principal fonte de conhecimento humano, trazendo implicações relevantes para as ciências, uma vez que se rompe com o pensamento aristotélico, ao rechaçar o

${ }^{13}$ Cf. Costa (1968, p. 48). 
conhecimento decorrente das experiências imediatas. A doutrina jusracionalista influencia os pensadores do século XIX, inspirando os códigos produzidos nesse momento histórico, em especial o Código Napoleônico. Posteriormente, a Escola das Pandectas aporta ao direito a noção de sistema, produzindo um método dogmático, estruturado a partir dos conceitos gerais, no qual categorias jurídicas são consideradas a expressão maior da lógica jurídica, portanto universais e imutáveis.

É dentro de tal contexto que são salientadas duas características dos direitos reais:

1. O irrealismo metodológico dos direitos reais, expressão da pouca permeabilidade da categoria às mudanças sociais; e

2. O imobilismo legislativo, caracterizado pelas poucas alterações legais no regime de direitos reais, que possui com uma de suas características tradicionais a tipicidade (MENEZES CORDEIRO, 1994, p. 218).

Todavia, a questão central está em estabelecer quais operações tais direitos corporificam, visto que a categoria expressa realidades econômicas pelas quais o homem opera no seu cotidiano. O processo de tipificação de um novo direito real passa pelo seu reconhecimento legal, contudo, justifica-se por conta de uma necessidade que se faz sentir no corpo social. Na temática em questão, qual seja, a dos novos direitos reais sobre bens públicos, pode-se afirmar que os mecanismos de tutela real foram utilizados para garantir a legitimação da posse de bens públicos através da regularização fundiária.

Questiona-se assim o irrealismo metodológico dos direitos reais. Isto porque, ainda que tenha havido um lento reconhecimento de situações fáticas que eram desconsideradas, progressivamente foram as mesmas efetivadas, até finalizar na outorga de um direito real, direito que goza de maior eficácia possível entre os direitos subjetivos. Deste modo, as alterações introduzidas na sistemática dos direitos reais pela Lei 11.481/07 parece, contrariamente, comprovar a permeabilidade das estruturas de direitos reais ao atendimento das necessidades sociais, ainda que numa velocidade menor do que a esperada, por se tratar de uma questão que toca ao legislador e não propriamente ao jurista.

A tipicidade legal, longe de configurar um simples imobilismo sem qualquer causa jurídica, guarda na eficácia decorrente da oponibilidade erga omnes o seu fundamento, que se justifica pelo fato de o direito ser não apenas oponível ao poder público em um bem de sua titularidade, mas também a terceiros. Por outro lado, outra crítica feita é que a estrutura conceitual que sustenta a construção dos direitos reais é ainda hoje erigida em torno do direito de propriedade, categoria 
jurídica que expressa a titularidade de uma coisa por parte do sujeito. A propriedade ocuparia um papel central no direito das coisas, e os outros direitos reais seriam apenas tratados como meros satélites do "direito subjetivo maior", e pouco explorados. ${ }^{14}$

Tratando-se do direito das coisas, aponta-se que a principal busca não seria por uma nova teoria geral dos direitos reais, mas por uma nova hermenêutica, ${ }^{15}$ que principie pela dinamização e pela concretização de institutos tradicionalmente pautados por grandes construções, com pretensão universalizante. A tarefa se torna possível apenas à medida em que se reconhece a necessidade de uma inter-relação dos direitos reais não só com os demais institutos do direito civil, mas também com outras áreas do conhecimento jurídico, numa postura clara de rejeição ao isolacionismo metodológico (ARONNE, 2001).

Tal hermenêutica torna-se possível pela integração sistemática, na perspectiva que se abre pela criação de um regime público-privatístico para a disciplina dos novos direitos reais. A confluência de regras públicas no conteúdo dos direitos reais decorre da integração sistemática e são fatores importantes para o desenvolvimento da ciência jurídica. Essa mutação dos direitos reais por parte de diplomas de direito público também vem sendo apontada como fruto do imobilismo das fontes clássicas, mas pode ser vista como algo positivo. Um exemplo salutar é a Lei 11.777/09, que prevê a legitimação da posse, que, devidamente registrada, constitui direito em favor do detentor da posse direta para fins de moradia e que tal direito, após o decurso do prazo de cinco anos, valerá como fundamento para a aquisição da posse por usucapião ${ }^{16}$.

Trata-se de medida inserida no programa de regularização fundiária de interesse social, no qual se legitima pela atribuição de eficácia jurídica a uma situação fática. A mens legis foi resolver os graves problemas sociais que decorrem da "propriedade informal", que resultam da ocupação desordenada das cidades, gerando situações imobiliárias irregulares e clandestinas, em especial as favelas e cortiços. A possibilidade de usucapião extrajudicial após cinco anos do seu registro, é uma

\footnotetext{
14 "A propriedade [...] não exsurge como uma relação una, mas, notadamente, como um complexo de relações que implicam, cada uma delas, novos direitos subjetivos que subsistem em função dela, como verdadeiros satélites, mas de vivência normalmente temporária" (SERPA LOPES, 2001, p. 97).

${ }^{15}$ Sobre a nova hermenêutica dos direitos reais, recomenda-se a leitura de Ricardo Aronne (2001). Gustavo Tepedino observa que, no direito civil brasileiro, notam-se duas grandes correntes bem definidas: de um lado, os estudiosos convencidos da importância da ordem pública constitucional para a definição dos institutos privatistas clássicos buscam a superação da rígida herança dogmática do século XIX; de outro lado, os defensores da concepção do Código Civil como centro orgânico das relações patrimoniais afirmam que sua evolução dogmática deflui de uma evolução histórica que decorre da valoração subjetiva do intérprete (2006, p. 399).

${ }^{16}$ A expressão é de Pietro Perlingieri (1999).
} 
importante medida no sentido ao permitir a atribuição de propriedade àqueles que deram uma destinação a um imóvel.

Não se pode olvidar que as noções jurídicas ganham corpo dentro do convívio social e que a atribuição de direitos, exclusivos ou não, sobre uma coisa, relaciona-se com o estabelecimento titularidades por meio de relações de pertinência e exclusão em relação a um objeto cogitado. A formalização reconhecimento registral das ocupações permite a concessão de títulos registráveis às pessoas de baixa renda que ocupam imóveis urbanos irregularmente, introduzindo-as no sistema formal de propriedade (DE SOTO, 2001, p. 60).

Diante dessa constatação, dar-se-á sequência à reflexão mediante a análise das condicionantes dos direitos direito das coisas, com o escopo de harmonizar a tensão que se coloca entre as estruturas jurídicas existentes e a realidade na qual elas estão inseridas. Entre novos e velhos dogmas, ${ }^{17}$ é preciso descobrir quais são as perspectivas que a esse respeito se apresentam (Cf. AMARAL, 1993, p. 45). Nisso desponta um novo caminhar, um mover que nos leva a atentar para a integração sistemática dos direitos reais no ordenamento jurídico contemporâneo.

\section{A DINAMIZAÇÃO DO DOMÍNIO E A CRIAÇÃO DE NOVOS DIREITOS REAIS}

Apesar das críticas supra-apontadas, que assinalam o imobilismo no método dos direitos reais, o eterno mestre Caio Mário, em sua obra Instituições do direito civil brasileiro - considerada uma referência obrigatória para o estudo do tema -, define o direito das coisas como "a província do direito privado mais sensível às influências de evolução social" (PEREIRA, 2004, p. 6). Atuais se fazem as suas palavras. Cumpre observar, contudo, que as grandes inovações dos direitos reais destinadas a provocar a dinamização do domínio têm partido prioritariamente de outros ramos do direito que não o direito civil, especialmente o direito público.

Diante da relativa inércia do direito privado, que continua preso ao elenco clássico dos direitos reais tipificados por lei, as respostas partem da intervenção do Estado em certos domínios, especialmente na questão da propriedade imobiliária, do direito de construir e das limitações administrativas. Tal confluência de fontes "não privatísticas" é utilizada como argumento a

\footnotetext{
17 No mesmo sentido, Karl Engisch ressalta o caráter prático da ciência jurídica: "Quando ao leigo se representa o jurista e o seu 'ofício', pensa-o como um homem que se ocupa das leis. Mas, ao pensar assim, o certo é que essa é uma das faces da realidade. Até o leigo sabe já que o prático do direito, que representa sem dúvida o protótipo do jurista, se ocupa da 'vida'. E o leigo sabe ainda mais: ele sabe que, para todo e qualquer indivíduo, o direito é uma força que tem incidência sobre o seu viver (2001, p. 74).
} 
confirmar a imutabilidade dos direitos reais, visto que as principais mudanças não partem das estruturas conceituais do direito civil (PEREIRA, 2004, pp. 229-30).

Todavia, tal assertiva é parcial e reducionista, por desconsiderar que o estabelecimento de vasos comunicantes entre os diversos ramos do direito reforça o caráter sistemático do ordenamento jurídico. A fonte da qual se originam as mudanças não apresenta especial relevância, mas sim sua incorporação pelo sistema jurídico, que é uno e opera de modo coerente e integrado. Afigura-se ilusória a perspectiva que reduz o fenômeno jurídico a compartimentos isolados das diversas partes do todo, como se fosse realmente possível separar seus elementos sem perder algo de essencial.

É impossível repartir a multiplicidade dos fatos da vida em pontos de vista jurídicos de valoração num sistema tão minuciosamente pensado de compartimentos estanques e imutáveis, como se bastasse destacá-los para os encontrar, um a um, em cada um desses compartimentos (LARENZ, 1997, p. 645). ${ }^{18}$ As diferentes normas e áreas do conhecimento jurídico estão em constante interação, condicionando-se mutuamente, de modo que as divisões da temática jurídica não significam que a realidade do ordenamento é divisível em diversos setores, sendo um totalmente autônomo em relação ao outro, de tal modo que possa ser proclamada sua independência. ${ }^{19}$

A ideia de sistema parte justamente da premissa de articulação entre um complexo de regras, de articulação de um conjunto de elementos entre os quais se possa definir alguma relação. Existem então elementos de um todo harmônico coordenados entre si e que funcionam como uma estrutura organizada, caracterizando um perfil comum, a partir do qual todos os componentes devem ser vistos. Negar isso significa partir de uma visão equivocada do que sistema representa, pois, como muito bem salienta José de Oliveira Ascensão, "as soluções jurídicas não são arbitrárias nem desconexas, integram-se num conjunto, de que participam. O significado de cada elemento só é estabelecido por essa integração no todo" (2001, p. 224).

\footnotetext{
18 Para o aprofundamento do tema, recomenda-se a excelente obra Pensamento sistemático e conceito de sistema na ciência do direito, de Claus-Wilhelm Canaris (1996), que propõe a reformulação da noção de sistema, fundando-o na adequação valorativa e na unidade interior, trazendo as ideias de mobilidade e abertura.

${ }_{19}$ Para o aprofundamento do tema, recomenda-se a excelente obra Pensamento sistemático e conceito de sistema na ciência do direito, de Claus-Wilhelm Canaris (1996), que propõe a reformulação da noção de sistema, fundando-o na adequação valorativa e na unidade interior, trazendo as ideias de mobilidade e abertura.
} 
Se a intermediação de outras disciplinas jurídicas tem sido o instrumento utilizado para ventilar as vetustas estruturas civilistas e adaptá-las às contingências históricas, tal confluência é muito bem-vinda e esperada, por trazer a atualização da dogmática tradicional e dar nova tônica à questão da tipicidade dos direitos reais. O apontado imobilismo dos direitos reais é apenas aparente, pois sua integração sistemática promove sua comunicação não só com a parte geral do Código Civil, mas também com outros ramos do direito, como o direito constitucional, o direito administrativo, o direito agrário e o direito urbanístico (ASCENSÃO, 2001, p. 230).

Essa articulação com o regime de direitos trazido por outros ramos do direito permite a dinamização de situações jurídicas que antes tinham conotações abstratas e afastadas da realidade. O reconhecimento de que as relações de apropriação e de senhorio do homem sobre uma coisa são determinadas pelo contexto econômico e sujeitas à evolução exige a compreensão contextualizada do intérprete e leva o legislador a intervir quando surgem situações que demandam especial tutela. E grande parte das previsões normativas implica uma referência a operações econômicas que já vinham sendo constituídas na realidade social e que são cristalizadas ou reconhecidas num novo dispositivo legal.

Dentro da tipicidade dos direitos reais há um tipo real e um tipo legal, que simbolizam respectivamente a práxis e a teoria. Tais tipos estão em constante comunicação; por detrás de um conceito rígido, há um tipo fluido e real, que pode provocar a alteração dos tipos legais (ASCENSÃO, 1968, pp. 24-7). A apreensão do regime de direitos reais num plano da realidade, e não num plano estereotipado, habilita o intérprete a reformular o elenco dos direitos reais (MENEZES CORDEIRO, 1994, pp. 230-1).

Atento às necessidades da sociedade brasileira, o legislador trouxe à baila a Lei $\mathrm{n}$. 11.481/07, que prevê medidas voltadas à regularização fundiária de interesse social em imóveis da União, dentre elas a criação de novos direitos reais, como forma de contemplar os programas habitacionais e de regularização fundiária de interesse social. O texto legislativo, voltado para os assentamentos de populações de baixa renda possui especial relevo no contexto habitacional nacional.

A regularização fundiária em imóveis do patrimônio público no país vem ocorrendo mediante um longo processo que engloba mecanismos de direito público e de direito privado. Iniciando pela atribuição de uma tutela meramente obrigacional aos ocupantes de imóveis públicos, passa pela legitimação da posse e caminha para a atribuição de direitos reais aos particulares, que passam a gozar da maior eficácia decorrente da sua oponibilidade erga omnes. 
Além disto, novos fracionamentos da propriedade são admitidos com vistas proporcionar a dinamização do domínio e a criação de garantias reais que estimulam a produção e o proveito do solo.

Progressivamente, os ajustes necessários a garantir a efetividade de programas já em desenvolvimento têm sido promovidos. E os direitos reais se configuram como mais um instrumento da política legislativa destinada a promover tal mudança.

\section{A LEI N. 11.481/07 E A NOVA SISTEMÁTICA DOS DIREITOS REAIS SOBRE OS BENS PÚBLICOS}

A ocupação desordenada do território urbano somada à ausência de uma política habitacional efetiva acabou por propiciar o surgimento de ocupações irregulares nos bens públicos por populações carentes. Desde a década de 60, várias famílias migraram dos seus locais de origem e passaram a ocupar algumas áreas periféricas das cidades, gerando bolsões habitacionais de miséria, sendo que tal realidade era solenemente ignorada pelo poder público.

Com a promulgação de CF de 1988, algumas questões relativas à regularização fundiária foram enfrentadas pelo constituinte que reconhece a função social das propriedades urbana e rural, impondo ainda uma política de desenvolvimento urbano ${ }^{20}$ e a possibilidade de desapropriação de imóvel rural por interesse social, para fins reforma agrária ${ }^{21}$. Contudo, a questão permanecia essencialmente problemática em se tratando de ocupação irregular em terrenos públicos, uma vez que o texto constitucional continuava a vedar a possibilidade de usucapião dos bens públicos, urbanos ou rurais ${ }^{22}$.

\footnotetext{
${ }^{20}$ Cf. Art. 182. A política de desenvolvimento urbano, executada pelo Poder Público municipal, conforme diretrizes gerais fixadas em lei, tem por objetivo ordenar o pleno desenvolvimento das funções sociais da cidade e garantir o bem- estar de seus habitantes. § 10 O plano diretor, aprovado pela Câmara Municipal, obrigatório para cidades com mais de vinte mil habitantes, é o instrumento básico da política de desenvolvimento e de expansão urbana.

$\S 2$ ㅇ A propriedade urbana cumpre sua função social quando atende às exigências fundamentais de ordenação da cidade expressas no plano diretor.

${ }^{21}$ Art. 184. Compete à União desapropriar por interesse social, para fins de reforma agrária, o imóvel rural que não esteja cumprindo sua função social, mediante prévia e justa indenização em títulos da dívida agrária, com cláusula de preservação do valor real, resgatáveis no prazo de até vinte anos, a partir do segundo ano de sua emissão, e cuja utilização será definida em lei.

Parágrafo único. A lei garantirá tratamento especial à propriedade produtiva e fixará normas para o cumprimento dos requisitos relativos a sua função social.

${ }^{22} \mathrm{Cf}$. Art. 183. Aquele que possuir como sua área urbana de até duzentos e cinquenta metros quadrados, por cinco anos, ininterruptamente e sem oposição, utilizando-a para sua moradia ou de sua família, adquirir-lheá o domínio, desde que não seja proprietário de outro imóvel urbano ou rural.
} 
A título de contextualização histórica, é importante notar que, face à impossibilidade de usucapião de bens públicos, e sendo uma realidade nacional a ocorrência de diversos conflitos fundiários e a ocupação de terras públicas, desde 2001 o poder público vem tomando algumas medidas que buscam flexibilizar o regime da posse desses bens e permitir o reconhecimento de situações outrora consideradas irregulares e desprovidas de tutela jurídica efetiva. O reconhecimento de situações práticas que não recebiam uma tutela jurídica efetiva é iniciado pela medida provisória 2.220/01, que traz o reconhecimento legal da concessão de uso especial para fins de moradia e cria o Conselho Nacional de Desenvolvimento Urbano.

Editada com o objetivo de tornar eficaz o artigo 183, parágrafo primeiro da Constituição e suprir a lacuna do veto presidencial aos artigos 15 e 20 do Estatuto da Cidade), que disciplinava a concessão de uso especial com fins de moradia, a medida provisória, dando efetividade à função social da propriedade ${ }^{23}$, trouxe em seu artigo $1^{\circ}$ a concessão de direito de uso para fins de moradia àqueles que preenchessem determinadas condições. ${ }^{24}$ Tais pessoas, anteriormente tratadas como simples detentores, progressivamente foram reconhecidas como possuidores através da celebração de contratos com o poder público que previam o uso para fins de moradia.

Da conversão da MP, surge a Lei n. 11.481/07, que trata da regularização fundiária de interesse social em imóveis da União, promove reformas na disciplina jurídica da ocupação de bens

$\S 1$ o O título de domínio e a concessão de uso serão conferidos ao homem ou à mulher, ou a ambos, independentemente do estado civil.

$\S 2$ o Esse direito não será reconhecido ao mesmo possuidor mais de uma vez.

$\S 3$ o Os imóveis públicos não serão adquiridos por usucapião.

Art. 191. Aquele que, não sendo proprietário de imóvel rural ou urbano, possua como seu, por cinco anos ininterruptos, sem oposição, área de terra, em zona rural, não superior a cinquenta hectares, tornando-a produtiva por seu trabalho ou de sua família, tendo nela sua moradia, adquirir-lhe-á a propriedade.

Parágrafo único. Os imóveis públicos não serão adquiridos por usucapião.

${ }^{23}$ Art. 5o Todos são iguais perante a lei, sem distinção de qualquer natureza, garantindo-se aos brasileiros e aos estrangeiros residentes no País a inviolabilidade do direito à vida, à liberdade, à igualdade, à segurança e à propriedade, nos termos seguintes: (...)

XXII - é garantido o direito de propriedade;

XXIII - a propriedade atenderá a sua função social;

Art. 170. A ordem econômica, fundada na valorização do trabalho humano e na livre iniciativa, tem por fim assegurar a todos existência digna, conforme os ditames da justiça social, observados os seguintes princípios: (..)

II - propriedade privada;

III - função social da propriedade;

24 "Aquele que, até 30 de junho de 2001, possuiu como seu, por cinco anos, ininterruptamente e sem oposição, até duzentos e cinquenta metros quadrados de imóvel público situado em área urbana, utilizandoo para sua moradia ou de sua família, tem o direito à concessão de uso especial para fins de moradia em relação ao bem objeto da posse, desde que não seja proprietário ou concessionário, a qualquer título, de outro imóvel urbano ou rural". 
públicos e estende a concessão de uso especial para fins de moradia aos terrenos de marinha e acrescidos. ${ }^{25}$ O texto legislativo altera o elenco dos direitos reais previstos no ordenamento jurídico brasileiro e promove mudanças nos direitos reais de garantia. No que se refere ao Código Civil, ele traz as seguintes inovações:

1. Institui a concessão de uso especial para fins de moradia e a concessão real de uso como direitos reais; e

2. Insere no artigo 1.473 do Código Civil os incisos VIII e IX, que permitem que o direito de uso especial para fins de moradia e o direito real de uso sejam objeto de hipoteca.

Quanto à legislação especial, ela adiciona o parágrafo 1으 e os incisos II, III e IV no Artigo 22 da Lei n. 9.514/97, possibilitando que o direito real de uso especial para fins de moradia e o direito real de uso, desde que suscetível de alienação, sejam objeto de alienação fiduciária, incluindo também a propriedade superficiária. Além disso, o artigo 13 da Lei n. 11.481/07 permite que a concessão de uso especial para fins de moradia e a concessão de direito real de uso (além do direito de superfície) sejam objetos de garantia real, além de assegurar sua aceitação pelos agentes financeiros no âmbito do Sistema Financeiro da Habitação (SFH).

Ao viabilizar a regularização urbana e qualificar situações meramente obrigacionais como direitos reais, busca-se o cumprimento dos ditames relativos à regularização da ocupação desordenada das áreas públicas. O reconhecimento de uma maior eficácia a situações nas quais é dado um destino socialmente desejável aos imóveis públicos fortalece a atribuição de titularidades reais como mecanismo de superação da pobreza e promoção do desenvolvimento das potencialidades humanas. A outorga de uma tutela jurídica mais eficaz aos ocupantes de um imóvel público ocorre pela transferência da posse direta deste a um particular, mantida intacta a propriedade pública.

Um aspecto importante da lei está em qualificar determinadas situações jurídicas, que anteriormente tinham caráter obrigacional - ou que não eram sequer admissíveis pelo ordenamento -, como situações jurídicas reais, o que abrange todo o regime jurídico inerente aos direitos reais, em especial a oponibilidade erga omnes. Apesar de se tratar de matéria de direito público - pois tais direitos são previstos essencialmente em bens públicos -, a inserção dos novos direitos no Código Civil traz maior segurança jurídica para a população de baixa renda e, em

\footnotetext{
${ }^{25}$ A concessão de uso especial para fins de moradia aplica-se às áreas de propriedade da União, inclusive aos terrenos de marinha e acrescidos, e será conferida aos possuidores ou ocupantes que preencham os requisitos legais estabelecidos na Medida Provisória n. 2.220, de 4 de setembro de 2001 (BRASIL, 1988).
} 
especial no caso do direito de uso especial para fins de moradia, torna efetivo um direito fundamental consagrado na Constituição da República.

A lei buscou concretizar a função social da propriedade pública ao reconhecer como direitos reais diversas modalidades de uso dos bens públicos. Situações fáticas que não tinham uma tutela real passam a ser titularizadas na forma de um direito subjetivo mais forte, oponível ao Estado. Todavia, o mero reconhecimento legal não realiza automaticamente suas finalidades, sendo desejável também uma atuação promocional do Estado. Aqui cabem algumas reflexões sobre a função que os direitos reais desempenham no ordenamento jurídico. Sabe-se que tais direitos gozam de determinadas características que têm por objetivo garantir a segurança jurídica por meio da cristalização de titularidades sobre coisas suscetíveis de apropriação.

A tipicidade e a necessidade de registro de títulos para a constituição do direito real são imprescindíveis para garantir as transações entre as pessoas e estabelecer um mínimo de certeza jurídica. Todavia, existem situações fáticas relevantes que não gozam de proteção jurídica em virtude do complexo convívio entre um sistema principiológico de tutela da propriedade e uma estrutura formal que se refere ao modo de aquisição. Por conta disso, é salutar a promoção de uma reflexão sobre a estrutura e a função dos direitos reais. Norberto Bobbio (1977) salienta que se aplica à teoria do direito a distinção entre a aproximação estruturalista e a aproximação funcional feita pelas ciências sociais para classificar o seu objeto de estudo. Ele aduz que, no estudo do fenômeno jurídico todo o desenvolvimento posterior à teoria kelseniana se concentrou no estudo da abordagem estrutural e que o perfil funcional tem sido estudado de modo insuficiente (p. 63). O livro foi escrito na década de 1970 e, desde então, algumas iniciativas têm procurado alterar o estado da arte das letras jurídicas e investigar "não só o que o direito é", mas também "para o que ele serve" (p. 38).

No que tange ao direito civil, Pietro Perlingieri sustenta que situações jurídicas subjetivas têm dois perfis: o normativo e o funcional (2002, p. 107). O perfil normativo atribui relevância jurídica à situação, seria uma norma de conduta que atribui juridicidade à situação. O perfil funcional determina o papel a ser desempenhado pela situação no ordenamento jurídico, isto é, o nível de relevância a ela atribuída. O foco exclusivo na propriedade cede espaço para novas titularidades, que expressam interesses dignos de tutela jurídica pelo texto constitucional e concretizam a funcionalização da propriedade pública. 
Acentuam alguns autores ${ }^{26}$ o aparente pleonasmo na expressão "função social da propriedade pública", pois o fato de um bem ser qualificado como público traria em si mesmo a noção de que já é direcionado a garantir o bem comum ou social. Na propriedade pública, o componente social já estaria presente em virtude da própria função do Estado, diversamente do que ocorre na propriedade privada, que teve novos contornos apenas a partir do novo modo de pensá-la - tratando-a precipuamente como um direito condicionado por sua função.

Tal linha de raciocínio questiona a utilidade da função social dos bens públicos, por ela expressar uma mera retórica tautológica que não encontra uma utilidade efetiva. Contudo, cabe lembrar que a Constituição da República não diferenciou a propriedade privada da pública e também previu a função social da cidade, que, a rigor, também é pública ou coletiva. E, pela função atribuída a tais bens, deve o poder público estabelecer a maximização de seu uso, conciliando todas as formas de uso cabíveis - desde que sejam compatíveis com a finalidade principal do bem afetado -, inclusive o uso privativo de bem público por particular em algumas hipóteses (DI PIETRO, 2010). É justamente o caso dos direitos reais de uso sobre bens públicos instituídos pela já citada Lei n. 11.481/07.

A iniciativa do legislador, contudo, traz também algumas dificuldades, uma vez que é inaugurado um regime jurídico híbrido, público-privado, que deve ser bem delineado e decifrado pelo intérprete. Partindo da premissa de que cabe ao direito civil definir os conceitos referentes aos direitos reais, a análise da lei terá por base o estudo dos direitos reais sobre coisa alheia e sua função na estrutura da teoria dos direitos reais

O Código Civil tem um de seus livros especialmente dedicado à disciplina dos direitos reais, e para cada direito real ali previsto há também um capítulo específico, inteiramente dedicado ao seu regramento; o mesmo, todavia, não ocorre com os novos direitos reais, que, apesar de inseridos no Código, restam disciplinados exclusivamente pelas normas de direito público. Por esse motivo, o estudo interdisciplinar e sistemático é essencial para estabelecer com precisão as fronteiras dos novos direitos, que não se confundem com os direitos de uso e de habitação, já previstos no diploma civilístico.

Fato é que, apesar de o diploma privatista não se configurar o locus por excelência para a regulamentação de questões atinentes ao direito público, o legislador optou por criar novos direitos reais que incidem sobre bens públicos pela alteração do Código Civil. Tal inserção ocorreu na esteira do movimento de publicização do direito privado e da promoção de verdadeiros vasos

${ }^{26}$ A polêmica questão é muito bem elucidada por Maria Sylvia Di Pietro (2006).

Revista de Direito da Cidade, vol. 08, no 1. ISSN 2317-7721 pp.404-432 424 
intercomunicantes entre o direito público e o direito privado que promovem a funcionalização das titularidades públicas.

Apesar dessa aproximação, não se pode descurar que cabe ao direito civil disciplinar os regramentos que ocorrem entre os particulares na esfera do direito privado, e a previsão de requisitos específicos para questões de direito público é excepcional, como na hipótese do artigo 41 do Código Civil, que traz expressamente a classificação dos bens públicos. Os conceitos basilares referentes aos direitos reais e a sua estrutura pertencem ao âmbito do direito privado.

Assim é que a propriedade é o direito real prototípico (ASCENSÃO, 2012, p. 279) perante o qual se colocam todos os outros direitos, ditos menores, que dela decorrem e em torno dela gravitam. Os sistemas de Civil Law, em especial os inspirados no modelo francês, diversamente dos sistemas de Common Law, consagraram a indivisibilidade do direito de propriedade e o número fechado dos direitos reais. Por isso a teoria da propriedade dividida, ou desmembramento, foi utilizada para explicar o surgimento de direitos reais menores: o fracionamento da propriedade em domínio útil e domínio direto faria com que houvesse um fracionamento da propriedade, de modo a atribuir a cada um deles determinadas faculdades.

Atualmente, a teoria que melhor explica a existência de direitos reais menores se expressa no princípio da elasticidade do domínio, o qual determina que a propriedade tende a se contrair e a se expandir, num movimento que pode apresentar certo dinamismo e fazer surgir outros direitos reais. A plasticidade da propriedade significa que ela tende a se tornar plena, apesar de as suas faculdades estarem nas mãos de sujeitos diferentes, que não necessariamente são proprietários, mas que possuem direitos sobre coisas que não lhes pertencem, as chamadas coisas alheias. (RUGGIERO, 1958, p.370).

Diversamente da propriedade, que tem como características fundamentais a perpetuidade e a plasticidade, os direitos reais sobre coisa alheia são limitados temporalmente, pois sua função é atribuir a um sujeito diverso do proprietário algumas das faculdades ou dos poderes do proprietário, tornando possível uma ampliação das formas de utilização da coisa. A propriedade sofre uma espécie de compressão em decorrência da constituição de um direito real limitado de uso ou gozo e readquire sua plenitude automaticamente assim que o prazo termina.

É o que ocorre com a concessão de direito real de uso e a concessão de uso especial com fins de moradia de bens públicos, que podem ser concedidos por tempo certo ou indeterminado. $O$ caráter perpétuo dos direitos reais sobre coisas alheias é incompatível com o nosso sistema 
jurídico, na esteira do que prevê o Artigo 70, § 3으 do Decreto-lei n. 271/67, com redação dada pela Lei n. 11.481, de 2007:

É instituída a concessão de uso de terrenos públicos ou particulares remunerada ou gratuita, por tempo certo ou indeterminado, como direito real resolúvel, para fins específicos de regularização fundiária de interesse social, urbanização, industrialização, edificação, cultivo da terra, aproveitamento sustentável das várzeas, preservação das comunidades tradicionais e seus meios de subsistência ou outras modalidades de interesse social em áreas urbanas.

Apesar de possuírem em comum o fato de serem institutos eminente de Direito Administrativo, a concessão de direito real de uso e a concessão de uso especial com fins de moradia de bens públicos possuem características diversas. A concessão de direito real de uso foi instituída pelo Decreto- Lei 271, de 28 de fevereiro de 1967, tendo sido alterada pela lei 11.481/07, que ampliou o rol de finalidades para as quais pode ser constituída a concessão, incluindo, dentre elas, a regularização fundiária de interesse social, o aproveitamento sustentável das várzeas, preservação das comunidades tradicionais e seus meios de subsistência ou outras modalidades de interesse social em áreas urbanas ${ }^{27}$.

Frise- que tal direito é resolúvel e difere essencialmente do direito real de uso já previsto no Código Civil, tendo por isso merecido enumeração à parte no rol dos direitos reais consagrados no diploma privatista. Enquanto a concessão de direito real de uso alcança terrenos públicos e particulares e admite transmissão por ato inter vivos ou causa mortis, o direito real de uso ${ }^{28}$

${ }^{27}$ Art. 70 É instituída a concessão de uso de terrenos públicos ou particulares remunerada ou gratuita, por tempo certo ou indeterminado, como direito real resolúvel, para fins específicos de regularização fundiária de interesse social, urbanização, industrialização, edificação, cultivo da terra, aproveitamento sustentável das várzeas, preservação das comunidades tradicionais e seus meios de subsistência ou outras modalidades de interesse social em áreas urbanas. (Redação dada pela Lei no 11.481, de 2007)

$\S 1$ 을 concessão de uso poderá ser contratada, por instrumento público ou particular, ou por simples têrmo administrativo, e será inscrita e cancelada em livro especial.

$\S 2$ 2o Desde a inscrição da concessão de uso, o concessionário fruirá plenamente do terreno para os fins estabelecidos no contrato e responderá por todos os encargos civis, administrativos e tributários que venham a incidir sôbre o imóvel e suas rendas.

$\S 3$ o Resolve-se a concessão antes de seu têrmo, desde que o concessionário dê à imóvel destinação diversa da estabelecida no contrato ou têrmo, ou descumpra cláusula resolutória do ajuste, perdendo, neste caso, as benfeitorias de qualquer natureza.

$\S 4$ ㅇ A concessão de uso, salvo disposição contratual em contrário, transfere-se por ato inter vivos, ou por sucessão legítima ou testamentária, como os demais direitos reais sôbre coisas alheias, registrando-se a transferência.

${ }^{28}$ Cf. Art. 1.412 do Código Civil: O usuário usará da coisa e perceberá os seus frutos, quanto o exigirem as necessidades suas e de sua família.

$\S 10$ Avaliar-se-ão as necessidades pessoais do usuário conforme a sua condição social e o lugar onde viver. $\S 20$ As necessidades da família do usuário compreendem as de seu cônjuge, dos filhos solteiros e das pessoas de seu serviço doméstico.

Revista de Direito da Cidade, vol. 08, no 1. ISSN 2317-7721 pp.404-432 426 
importa a utilização pelo usuário de coisa alheia móvel ou imóvel, de acordo com as suas necessidades e as de sua família e não pode ser cedido, a qualquer título, ainda que gratuito, por se tratar de direito personalíssimo, atribuído intuitu personae.

Como citado anteriormente, a concessão de direito real de uso para fins de moradia foi inserida no ordenamento jurídico pátrio pela MP 2220/01. O disposto no artigo $1^{\circ}$. MP e semelhante aos requisitos que o artigo 1240 do Código Civil traz para que seja reconhecida a usucapião, dentre eles:

1. Posse ininterrupta e sem oposição até 30 de junho de 2001;

2. Ocupação pelo prazo de cinco anos, com finalidade de moradia do possuidor ou de sua família;

3. O imóvel público deve estar situado em área urbana; e

4. Sua metragem não pode ultrapassar duzentos e cinquenta metros quadrados.

No que tange ao direito de uso especial com fins de moradia, também é fundamental o cumprimento da finalidade que ensejou sua constituição: o imóvel público deve ser utilizado efetivamente com fins de moradia para que o ocupante faça jus à concessão. A finalidade é essencial, caso contrário, a lei não incidirá, pois estabeleceu expressamente um uso específico, reconhecendo uma titularidade real sobre um bem público destinado à moradia de um particular. Por seu turno, a concessão de direito real de uso não exige uma finalidade específica, bastando que o destino dado ao bem, isto é, o uso do bem pelo particular, seja economicamente útil ao usuário, que pode exercer uma ampla gama de atividades. Tal direito concretiza também a dinamização do domínio por meio do desdobramento dos poderes inerentes à propriedade.

Outro ponto relevante no que concerne ao dinamismo dos direitos reais são as inovações concernentes à alienação fiduciária e à hipoteca. Tradicionalmente, certas categorias de bens não podem ser hipotecadas, como, por exemplo, o bem de família, os bens gravados com cláusula de inalienabilidade, além dos próprios direitos reais (RUGGIERO, 1958 p. 575). A Lei n. 11.481/07 amplia o objeto da hipoteca e permite que o direito real de uso especial para fins de moradia e o direito real de uso sejam objetos dessa garantia real, o que reforça o caráter econômico das situações jurídicas tuteladas e aporta mobilidade ao sistema de garantias reais.

A rigor, os bens objetos de hipoteca devem ser alienáveis, o que nem sempre ocorre no caso em questão. Veja-se o exemplo dos terrenos de marinhas, bens públicos inalienáveis sobre os quais podem incidir direitos reais alienáveis. Como bem ensina Roberto de Ruggiero, é possível que 
um direito seja objeto de outro direito, mas, em última análise, "é sempre uma coisa que, na figura dos direitos sobre direitos, é seu objeto concreto" (1958, p. 237).

Na esteira da dinamização do uso e de sua transformação em valor jurídico que pode ser inserido na esfera do Sistema Financeiro Imobiliário, os direitos mencionados passaram a ser também objetos de alienação fiduciária; em se tratando de direito real de uso, todavia, tal possibilidade é admitida apenas quando tal direito é alienável, no que andou bem o legislador, disciplinando-o de modo coerente com a estrutura dos direitos e das garantias reais.

Tais alterações têm como função promover a mobilidade das faculdades proprietárias em prol de uma racionalidade econômica que contribua para o máximo aproveitamento da coisa. A propriedade pública permanece íntegra - pela característica que possui de se expandir até a sua compressão máxima - porém, de certa forma, limitada no que concerne ao pleno gozo de todas as utilidades que a coisa produz, que serão fruídas pelos beneficiários da concessão.

A geração de novas utilidades decorrentes da concessão de um direito real pode a circulação de riquezas e geração de capital para o sustento das pessoas beneficiadas pela concessão. De igual modo, o reconhecimento formal das titularidades reais dos menos favorecidos e a transformação de uma situação fática irregular em ativos pode promover a melhoria da qualidade de vida das pessoas de baixa renda e inseri-las nos benefícios do sistema formal de propriedade, que gera capital e a saída da informalidade (DE SOTO, 2001, p. 60).

Se, por um lado, o objetivo de tal previsão é promover uma valorização das relações econômicas - pois o usuário poderá celebrar contratos de financiamento e de abertura de créditos para projetos habitacionais e empresariais -, por outro lado, gera dificuldades, caso o devedor não tenha condições de honrar o pagamento das prestações, o que não deve ser desconsiderado, em especial pelas razões sociais da atribuição de tutela jurídica.

Se o direito real foi conferido a determinadas pessoas em virtude de situações de fato urgentes e que necessitavam de uma regularização, em especial no caso da moradia, a possibilidade de o conferir em garantia pode enfraquecer a própria segurança jurídica dada a essas pessoas. Todavia, para que se pudesse viabilizar tais operações de modo seguro para a população de baixa renda, parece-nos que seria adequado atribuir algum papel regulador Estado neste tipo de operação financeira, em especial no que tange aos juros e condições gerais de contratação. Outra medida interessante seria promover a assistência necessária da Defensoria Pública nos casos de contratos envolvendo a prestação de garantias decorrentes de direitos reais sobre bens públicos por pessoas de população de baixa renda. 


\section{CONCLUSÃO}

A Lei n. 11.481/07 tem reflexos importantes no sistema de direitos reais previsto no Código Civil e traz mudanças na propriedade pública, ao permitir ao possuidor do bem público uma tutela reforçada, de caráter real. Promoveu ainda o dinamismo das titularidades reais, ao ampliar o objeto dos direitos reais de garantia e atribuir valor econômico e de circulação. Em realidade, a doutrina publicista já admitia a atribuição de efeitos reais a tais contratos, e sua inserção no rol exaustivo dos direitos reais previstos no Código foi um modo de concretizar legalmente um entendimento que era apenas doutrinário, trazendo segurança jurídica para o usuário.

A previsão do direito real de uso especial para fins de moradia e o direito real de uso como requisitos objetivos da hipoteca promove a dinamização das relações econômicas e a valorização do mercado imobiliário, permitindo que o usuário celebre contratos de financiamento e de abertura de créditos para projetos habitacionais e empresariais. A inclusão do direito de superfície como requisito objetivo da hipoteca é compatível com o caráter autônomo que tal direito proporciona ao superficiário, que promove intensa atividade econômica no bem e tem a possibilidade de ceder o direito em apreço de forma gratuita ou onerosa.

A dinamização das garantias reais configura iniciativa louvável, contudo se deve fazer atenção para que não haja o desvirtuamento das finalidades para as quais esses direitos foram outorgados. O direito especial real de uso para fins de moradia foi o reconhecimento da relevância jurídica de determinadas situações, de fato urgentes, e que necessitavam de uma regularização. A possibilidade de o dar em garantia hipotecária consagra o caráter dinâmico dos direitos reais no contexto contemporâneo, porém pode enfraquecer a própria segurança jurídica dada a essas pessoas, no caso em que a transferência do uso se faz necessária para assegurar o pagamento da dívida.

Nesse particular, a fim de evitar problemas, seria de bom tom inserir alguns dispositivos legais no Código Civil sobre os novos direitos reais criados, ao menos em seus contornos principais, a fim de tornar menos fragmentado o regime jurídico desses direitos. A norma jurídica por si só não resolve problemas concretos, ainda que seja decisiva para tanto. Cabe ao intérprete, usando de uma hermenêutica integradora, fazer valer a mens legis, tornando efetivo o acesso à moradia e a dinamização das garantias reais. Os instrumentos trazidos são mecanismos de transformação da propriedade que estão de acordo com as suas novas exigências sociais e podem servir como ferramentas eficazes para atenuar a crise habitacional que se instala nos grandes centros urbanos 
brasileiros, possibilitando que os direitos reais atuem como instrumento de regularização fundiária de interesse social.

\section{REFERÊNCIAS}

AMARAL, Francisco. "Racionalidade e sistema no direito civil brasileiro". Revista de Direito Civil, Imobiliário, Agrário e Empresarial, n. 63, jan.-mar. 1993.

ANTUNES VARELA, João de Matos. Das obrigações em geral, vol. I. 10. ed. Almedina: Coimbra, 2000.

ARONNE, Ricardo. Das raízes aos fundamentos contemporâneos. Rio de Janeiro: Renovar, 2001.

ASCENSÃO, José de Oliveira. As relações jurídicas reais. Lisboa: Livraria Moraes Editora, 1962.

A tipicidade dos direitos reais. Petrony: Lisboa, 1968.

O direito: introdução e teoria geral. 2. ed. revista, atualizada e ampliada. Rio de Janeiro: Renovar, 2001.

Direito civil - reais. 5. ed. Coimbra: Coimbra Editora, 2012.

BEVILÁQUA, Clóvis. Theoria geral do direito civil. 2. ed. Rio de Janeiro: Francisco Alves, 1929.

Direito das coisas, vol. I. Rio de Janeiro: Forense, 1956.

BOBBIO, Norberto. Dalla struttura alla funzione - nuovi studi di teoria del diritto. Milão: Edizioni di Comunità, 1977.

BRASIL. Constituição da República Federativa Brasil. Presidência da República. Casa Civil. Subchefia para Assuntos Jurídicos, 1988.

CANARIS, Claus-Wilhelm. Pensamento sistemático e conceito de sistema na ciência do direito. 2. ed. Lisboa: Calouste Gulbenkian, 1996.

COSTA, Mário Júlio de Almeida. Direito das obrigações. Coimbra: Atlântida, 1968.

DANTAS, Francisco Clementino de San Tiago. Programa de direito civil III: direito das coisas. 3. ed. Revisão do texto e anotações de José Gomes de Bezerra Câmara e atualização de Laerson Mauro. Rio de Janeiro: Editora Rio, 1984.

DI PIETRO, Maria Sylvia Zanella. Uso privativo de bem público por particular. São Paulo: Atlas, 2010. "Função social da propriedade pública". Revista Eletrônica de Direito do Estado, n. 6, abr.-jun. 2006, pp. 1-4. Disponível em: http://nute.ufsc.br/moodle/biblioteca_virtual/admin/files/funcao_social_da_propriedade_publica_ aula_10___parte_i.pdf. Acesso em: 3 jul. 2015.

ENGISCH, Karl. Introdução ao pensamento jurídico. 8. ed. Lisboa: Calouste Gulbenkian, 2001.

ESPÍNOLA, Eduardo. Posse, propriedade, compropriedade ou condomínio, direitos autorais. Trad. R. R. Gama. Campinas: Bookseller, 2002. 
FACHIN, Melina Girardi; PAULINI, Umberto. "Problematizando a eficácia dos direitos fundamentais nas relações entre particulares: ainda e sempre sobre a constitucionalização do ireito civil". In TEPEDINO, G.; FACHIN, L. (orgs.). Diálogos sobre direito civil, vol. II. Rio de Janeiro: Renovar, 2008.

FACHIN, Luiz Edson. Estatuto jurídico do patrimônio mínimo. Rio de Janeiro: Renovar, 2001.

GROSSI, Paolo. História da propriedade e outros ensaios. Trad. Luiz Ernani Fritoli e Ricardo Marcelo Fonseca. Rio de Janeiro: Renovar, 2006.

LARENZ, Karl. Metodologia do estudo do direito. 3. ed. Trad. José Lamego. Lisboa: Calouste Gulbenkian, 1997.

MAURO, Roberta. "A propriedade na Constituição de 1988 e o problema do acesso aos bens". In TEPEDINO, G.; FACHIN, L. (orgs.). Diálogos sobre direito civil, vol. II. Rio de Janeiro: Renovar, 2008.

MENEZES CORDEIRO, António Manuel da Rocha. Estudos de direito civil, vol. I. Coimbra: Almedina, 1994.

NADER, Paulo. Curso de direito civil - direito das coisas, v. 4. 3. ed. revista e atualizada. São Paulo: Forense, 2006.

PEREIRA, Caio Mário da Silva. Instituições de direito civil - direitos reais, v. 4. 18. ed. atualizada por Carlos Edison do Rego Monteiro Filho. Rio de Janeiro: Forense, 2004.

PERLINGIERI, Pietro. Introduzione alla problematica della "proprietà". Collana lezioni della Scuola di Specializzazione in Diritto Civile dell'Università di Camerino. Napoli: Edizioni Scientifiche Italiane, 1988.

Perfis do direito civil. Rio de Janeiro: Renovar,1999.

RADBRUCH, Gustav. Filosofia do direito. 6. ed. Trad. Cabral de Moncada. Coimbra: Armênio Amado/Coimbra Editora, 1997.

RAMOS, Carmem Lúcia Silveira. "Constitucionalização do direito privado e a sociedade sem fronteiras. In: FACHIN, L. (org.). Repensando os fundamentos do direito civil brasileiro contemporâneo. Rio de Janeiro: Renovar, 1998.

RODOTÀ, Stefano. Il terribile derecho: estudios sobre la propriedad privada. Trad. L. Díez-Picazo. Madri: Civitas, 1981.

RUGGIERO, Roberto de. Instituições de direito civil, vol. II. Direito de família, direitos reais e posse. São Paulo: Saraiva, 1958.

SERPA LOPES, Miguel Maria de. Curso de direito civil, vol. VI. 18. ed. atualizada por José Serpa Santa Maria. Rio de Janeiro: Freitas Bastos, 2001.

TEPEDINO, Gustavo. "Teoria dos bens e situações subjetivas reais". In Temas de direito civil. Rio de Janeiro: Renovar, 2006. 
Trabalho enviado em 08 de outubro de 2015.

Aceito em 18 de fevereiro de 2016. 